\title{
$\angle$ Research Square \\ Predictive Value of Serum Aurora A, Thymidine Kinase 1, and HER3/ErbB3 in Breast Cancer Patients Before Neoadjuvant Treatment
}

\section{Pawel Winter ( $\nabla$ pawel.winter@pib-nio.pl )}

Breast Cancer and Reconstructive Surgery Department; Maria Sklodowska-Curie National Research Institute of Oncology, Warsaw

\section{Beata Kotowicz}

Department of Pathology and Laboratory Diagnostics, Laboratory of Tumor Markers, Maria

Sklodowska-Curie National Research Institute of Oncology, Warsaw

\section{Malgorzata Fuksiewicz}

Department of Pathology and Laboratory Diagnostics, Laboratory of Tumor Markers, Maria

Sklodowska-Curie National Research Institute of Oncology, Warsaw

\section{Maria Kowalska}

Department of Pathology and Laboratory Diagnostics, Laboratory of Tumor Markers, Maria

Sklodowska-Curie National Research Institute of Oncology, Warsaw

\section{Agnieszka Jagiello-Gruszfeld}

Breast Cancer and Reconstructive Surgery Department; Maria Sklodowska-Curie National Research Institute of Oncology, Warsaw

\section{Zbigniew Nowecki}

Breast Cancer and Reconstructive Surgery Department; Maria Sklodowska-Curie National Research Institute of Oncology, Warsaw

\section{Research Article}

\section{Keywords:}

Posted Date: January 12th, 2022

DOI: https://doi.org/10.21203/rs.3.rs-1233138/v1

License: (1) (i) This work is licensed under a Creative Commons Attribution 4.0 International License. Read Full License 


\section{Abstract}

Further personalization is needed to improve the outcomes of breast cancer treatment. It is necessary to find new inexpensive and easily evaluated predictive markers. In this study, we determined serum level of Aurora A (AURKA), thymidine kinase 1 (TK1) and human epidermal growth factor receptor type 3 (HER3) by enzyme immunoassay ELISA. We collected peripheral blood sera of 119 women with breast cancer before neoadjuvant treatment and the control group of 47 randomly selected healthy women. After treatment we analyzed clinical data: age, initial TNM stage, tumor receptors expression: estrogen (ER), progesterone (PGR), epidermal growth factor receptor type 2 (HER2), Ki67, histological malignancy grade, biological subtype, and response to neoadjuvant treatment in residual cancer burden (RCB) classification. Pathologic complete response (PCR) was achieved in 41 patients (34.45\%). In univariate analysis patients with higher AURKA levels were more likely to obtain PCR $(p=0.039)$. In multivariate analysis we used the logit regression model with PCR as the dependent. The effect of AURKA concentration $\geq 4.75 \mathrm{ng}$ / $\mathrm{mL}$ on the chance of achieving PCR was found (OR: $3.5 ; 95 \% \mathrm{Cl}: 1.2-10.1 ; \mathrm{p}=0.023$ ). Other significant PCR factors included: node status (OR: 0.503; $95 \%$ Cl: 0.263-0.965; $p=0.039$ ), negative PGR expression (OR: $0.104 ; 95 \%$ Cl: $0.038-0.284 ; p<0.001$ ), and Ki67 >20\% (OR: 5.44; 95\% Cl: 1.24-23,9; $p<0.025$ ). There was no significance in marker concentrations and clinical features nor between breast cancer patients and control group. The outcomes suggest that serum AURKA level is a potential PCR prediction marker in neoadjuvant breast cancer treatment. Further studies are needed to confirm our observations.

\section{Introduction}

Breast cancer (BC) is the most common malignant neoplasm and the leading cause of cancer death among women worldwide. It is estimated that in 2020 over 2.26 million new cases of BC among women were diagnosed worldwide, and almost 685,000 women died from this cancer [1]. BC is a heterogeneous disease with a very complex biology. According to DNA sequencing and gene expression profiling studies, there are no two identical neoplasms at the molecular level $[2,3]$. Based on the expression of tissue markers: estrogen receptor (ER), progesterone receptor (PGR), epidermal growth factor receptor type 2 (HER2) and Ki67, invasive BC is classified into five main biological subtypes - luminal A (LA), luminal $B$ (LB), luminal B HER2 enriched (HER2-LB), non-luminal HER2 positive (HER2-NL) and triple negative (TNBC). Tissue markers play both prognostic and predictive role in BC management. Neoadjuvant treatment (NAT) should be considered in all patients, who may be eligible for systemic treatment. There are no proven differences in overall survival (OS) and disease-free survival (DFS) between NAT and adjuvant treatment [4]. NAT is an important tool for reducing staging and treatment response monitoring. Pathological complete response (PCR) archived after NAT has proven beneficial long-term effect on DFS and OS, especially in TNBC and HER2 positive cancers [4]. There are different pathologic PCR reporting systems - AJCC-TNM, B18, Miller-Payne, modified Nottingham scale, Pinder and Residual Cancer Burden (RCB), the preferred in research is the RCB [5]. RCB is an independent prognostic factor for DFS and OS, moreover it can select patients with a high risk of recurrence and poor prognosis [6-8]. In LivingstoneRosanoff study of 38,864 patients treated with NAT in 2010-2013, postoperative PCR was obtained in 
only $19 \%$ cases [9]. Personalization of BC therapy improves outcomes and reduces costs and toxicity [10, 11]. In earlier studies from our department PCR was archived in 55\%-87\% patients with HER2-NL and HER2-LB who received TCH (docetaxel, carboplatin, trastuzumab) and TCH+P (docetaxel, carboplatin, trastuzumab + pertuzumab) NAT regimens $[12,13]$. Despite the significant advances in recent years, treatment results are still not satisfactory, and it is unknown why some patients with the same cancer subtype benefit from treatment and others do not. One of the newly available and validated prognostic tools are multi-parameter genetic tests e.g. Oncotype DX, Mammaprint, which can be used as independent predictors in the qualification to adjuvant treatment $[11,14]$. These genetic tests require formalin fixed paraffin embedded tumor tissue samples, moreover genetic testing is expensive and not widely available. Ideal biomarker should have high sensitivity and specificity, could be determined at any stage of treatment in a cheap, easily accessible, non-invasive way, and the obtained results should be reproducible and objective. Many of these criteria may be met by potential peripheral blood (PB) markers. PB can be easily divided into fractions containing selected groups of substances. After centrifugation of whole blood with the addition of a clotting activator, serum is obtained, which may contain potential markers - proteins, metabolites, lipids, autoantibodies, miRNA and ctDNA [15]. Researchers in past have selected several serum BC markers such as: CA 15-3, CEA, tissue antigen polypeptide (TPA) and tissue specific polypeptide antigen (TPS). Unfortunately, due to low sensitivity and specificity, none of them is currently recommended in BC management [16-19]. Therefore, new breast cancer biomarkers are still being explored. One of the concepts is the analysis of enzymes involved in the regulation of the cell cycle, carcinogenesis, angiogenesis, cell adhesion and migration, which could also be a target for anti-cancer therapies. Aurora A - (AURKA) belongs to the AURORA serine-threonine kinases. The family of proteins was discovered over three decades ago during research of the factors responsible for spindle formation in budding yeast [20]. In mammalian cells tree different AURORA kinases were discovered - A, B and C, whose main function is in general the regulation of cytoskeleton, chromosomes, and cell division processes. AURKA is a protein that regulates the cell cycle process. Inhibition of its activity causes the arrest of the cell cycle at the transition from the G1 to S phase [21]. Its level increases in the G2 / M phase [22]. AURKA binds to microtubules, plays key role in spindle formation and positioning [23]. It is involved in centrosome duplication and separation, chromosome alignment and cytokinesis [24-27]. AURKA phosphorylates and regulates many proteins and genes responsible for cell cycle checkpoints, including: CDK1 / Cyclin B, BRCA1, BRCA2, p53 / TP53, TACC-3, RAS [22, 28-30]. Regardless of the kinase function, AURKA in cell nuclei shows the activity of a transcription factor, participates in the assembly and stabilization of the replisome [21]AURKA is also associated with mitochondria, Golgi apparatus, cytoskeleton, affects the process of cell migration and invasion, and the rate of metabolism by regulating ATP synthesis [31, 32]. AURKA enhances the phenotype of neoplastic stem cells, increases their survival, ability to migrate and invade [33].AURKA expression shows tissue specificity (testes, skeletal muscles, thymus, spleen), increased levels are found in colon, breast, ovarian, cervical, neuroblastoma, prostate, and bladder cancer cells. AURKA expression can be considered as a neoplastic marker in breast cancer [34]. The human epidermal growth factor receptor 3 (HER3) belongs to transmembrane tyrosine kinase receptors (EGFR) [35]. In addition to HER3, three other proteins have been identified - HER1, HER2, and HER4. HER3 consists of an extracellular domain, a transmembrane portion, and an intracellular domain 
[36]. In addition to the $180 \mathrm{kDa}$ glycoprotein, alternative splicing also produces p45 and p85 glycoproteins from the ERBB3 gene, which lack a transmembrane portion and an intracellular domain; are referred to as soluble HER3 (sHER3) [37]. HER3 is activated extracellularly by binding to two ligands - neuregulin 1 and neuregulin 2 [38]. The intracellular domain of HER3 does not function as a kinase by itself. To demonstrate intracellular activity and signal transduction, HER3 requires heterodimer formation with other proteins of the EGFR group, e.g., HER2. HER2 / HER3 heterodimers show oncogenic activity by activating intracellular pathways such as: (PI-3K) / AKT [39], MAPK, RAS-ERK, which stimulate proliferation, angiogenesis, migration and increase the survival of neoplastic cells [40]. In some patients with resistance to anti-HER2 therapy, elevated levels of neuregulins are observed. According to studies, the HER3 activating pathways to the formation of HER2 / HER3 heterodimers may play a key role in the mechanism of resistance of HER2-positive tumors to trastuzumab treatment and the resistance of LB tumors to hormone therapy [41]. HER3 has been shown to be overexpressed in breast, bladder, ovarian, prostate, melanoma, and neuroblastomas [42]. HER3 has been strongly overexpressed in metastatic foci of breast cancer, especially in the brain. HER3 overexpression is also associated with resistance to hormone therapy, anti-HER2 therapy, and taxanes. HER3 inhibitors in cancer treatment are being investigated [43]. In recent years, methods for determining HER3 in serum have been described for further research [44]. Thymidine kinase 1 (TK1) is a cell cycle phase-dependent enzyme involved in DNA synthesis [45]. Thymidine kinase exists in cells as two isoenzymes: TK1 and TK2. TK1 is involved in the thymidine phosphorylation reaction, which is a necessary step in its incorporation into DNA. TK2 is found in the mitochondria. TK1 converts deoxytimidine (dT) to deoxytimidine monophosphate (dTMP) by transferring phosphate from ATP. The monophosphate is further phosphorylated to deoxymidine triphosphate (dTTP), which is incorporated into DNA. Intracellular TK1 most often occurs in the form of homodimers. When DNA is damaged, TK1 is converted to the most active form of tetramer. TK1 activity is highest during the G1 / S phase and is almost completely lost during mitosis [45]. In cancer cells, TK1 activity may remain increased throughout the cell cycle. TK1 is released into the extracellular space from cells that die during division, which is characteristic of neoplastic cells [46]. TK1 activity in plasma has been found to be higher in patients with hematological cancers, breast, lung, colon, stomach, ovarian and cervical cancer, and may serve as a proliferative marker [47]. In solid tumors, serum TK1 levels have been shown to correlate with disease stage [46]. High levels of TK1 in breast cancer have been shown to correlate with poorer OS and PFS [48]. The use of TK1 as a target for cancer therapy is also being analyzed. The aim of this study is to evaluate prognostic value of AURKA, HER3 and TK1 in in breast cancer treated with neoadjuvant chemotherapy.

\section{Materials And Methods}

We performed a single center, prospective, observational study according to the ethical standards of the Declaration of Helsinki. The samples were taken after informed consent from all the study participants. The protocol was approved by the Bioethics Committee at the Maria Sklodowska-Curie National Research Institute of Oncology in Warsaw (NIO-PIB) (authorization no. 34/219). Study design is presented in Figure 1. 


\section{STUDY POPULATION AND PATIENT SELECTION}

We randomly selected a group of 252 women who were diagnosed with breast cancer in 2017-2018 at the Breast Cancer and Reconstructive Surgery Department, NIO-PIB. In 2020 we collected and analyzed baseline clinical data (prior to treatment): age, core needle biopsy -histological type, ER, PGR, Ki67 and HER2 expression, biological subtype, grade of histological malignancy in the NGS classification, UICC / AJCC $8^{\text {th }}$ TNM clinical classification, then the course and type of treatment - NAT, surgery, pathological response to NAT in RCB classification, adjuvant therapy and radiotherapy. A group of 119 patients who received NAT, was qualified for the further part of the study and the determination of markers. The control group consisted of 47 randomly selected healthy women.

\section{SAMPLES PREPARATION AND TESTING}

Sera from peripheral blood samples were obtained and secured up to 14 days before the start of treatment. Peripheral blood was collected in the tubes containing the clotting activator, then the samples were centrifuged for $15 \mathrm{~min}$ at $2600 \mathrm{rpm}$ and $5^{\circ} \mathrm{C}$. The sera obtained in this way were poured into separate test tubes in a volume of $0.5 \mathrm{ml}$ and stored in low-temperature freezers $\left(-70^{\circ} \mathrm{C}\right)$ until the analysis was performed. The tested parameters were determined twice using the enzyme-linked immunosorbent assay (ELISA) method: Human ERBB3 ELISA KIT by Biorbyt, Human hThK 1- by EIAAB and Human AURKA (Aurora A) using Fine Test kits.

Calibrators, controls, and the test serum were added to the microtiter plate wells coated with a specific monoclonal antibody. After incubation and washing out of excess reagents, a polyclonal antibody conjugated to the labeling enzyme was added. After re-incubation and removal of excess reagents, the substrate solution - hydrogen peroxide and the chromogen - tetramethylbenzidine were added in the next step. The enzyme reaction was stopped by adding $2 \mathrm{~N}$ sulfuric acid. The concentrations of the studied biomarkers were determined by measuring the optical density on the BIO-TEK Elx 800 spectrophotometer at a wavelength of $450 \mathrm{~nm}$.

\section{STATISTICAL ANALYSIS}

SPSS Statistics version 23 by IBM was used for statistical calculations. Continuous variables of biomarker concentrations were categorized. Cut-offs were chosen to divide patients into three equal groups. In the first step, a one-way analysis was performed using the $\chi 2$ test of independence, and in the second step, a multivariate analysis using a logit regression model with the PCR variable as the dependent. The model was built based on the following classical clinical variables that may affect the response to treatment: TNM stage, malignancy grade and the status of receptors defining the biological subtype: ER, PGR, HER2 and Ki67. The fitted model was used to test the predictive value of the investigated markers. In the modeling process, the method of stepwise elimination of variables with standard levels of inclusion $(p<0.05)$ and exclusion $(p>0.1)$ was used. 
To estimate the predictive value, the distribution of marker concentrations depending on PCR after NAT was analyzed with non-parametric Mann-Whitney test and the ROC curve. The optimal cut-off points were determined and for these points: sensitivity, specificity, positive and negative predictive value were calculated. Additionally, the distributions of the analyzed biomarkers in women with breast cancer and healthy women were compared and their diagnostic potential was assessed.

\section{EXPLORATIVE ANALYSIS}

Marker concentrations and the age of the patients were analyzed using the Spearman's rank correlation test. The adopted level of statistical significance $a=0.001$. Next, $37 \chi 2$ tests of independence were carried out to characterize the concentrations of the tested markers in relation to clinical data. The concentration cut-offs were chosen to divide patients into three equal groups, which offers the best chance of detecting relationships between the test variables. Considering the Bonferroni correction for multiple testing, individual tests were performed at the level of statistical significance equal to 0.001 .

\section{Results}

\section{PATIENT CHARACTERISTICS}

Overall, 119 women were qualified for the determination of marker concentrations (Figure 1). The median age and the interquartile range were 53 (IQR: 42-63) years. Tumors up to $5 \mathrm{~cm}$ in size (T1 and T2) were diagnosed in 81 patients, and no metastases in the regional lymph nodes (N0) were detected in 52 patients. At the time of treatment initiation, 8 women had stage IV (M1) disease. In 111 women the disease was diagnosed with intermediate and high NGS histological grade (G2 and G3). The largest group of patients were patients with luminal neoplasms - (37-LB and 13 LA), and in 45 cases expression of the HER2 receptor was detected. In the study group, 44 patients received chemotherapy according to the $\mathrm{TCH} / \mathrm{TCH}+\mathrm{P}$ regimen (36.9\%) as neoadjuvant therapy (36.9\%), 61 received sequential treatment $(4 \times A C+12 x P X L)(51.26 \%)$, and 14 patients received hormonal treatment (11.76\%). 41 (34.45\%) patients achieved PCR which was further analyzed with clinical features by $\chi 2$ test $(p<0,05)$. Histological grade $(p$ $=0.0078)$, biological subtype $(p=0.0003)$ had significant correlation. There was no correlation between PCR rates and tumor size in the TNM classification $(p=0.3584)$, or the status of the lymph nodes $(p=$ 0.2435). The detailed characteristics of the study group and PCR outcomes are presented in Table 1 
Table 1

Patient characteristics and PCR outcomes

\begin{tabular}{|c|c|c|c|}
\hline \multicolumn{4}{|l|}{$n=119$} \\
\hline Age & \multicolumn{3}{|c|}{52,4 years $(31-77)$} \\
\hline Mean (min, max) & \multicolumn{3}{|l|}{53 years } \\
\hline \multicolumn{4}{|l|}{ Median } \\
\hline $\mathrm{ER}+$ & \multicolumn{3}{|l|}{$74(62.18 \%)$} \\
\hline PGR + & \multicolumn{3}{|l|}{$61(51.26 \%)$} \\
\hline HER2 + & \multicolumn{3}{|l|}{$45(37.82 \%)$} \\
\hline Ki67 & \multicolumn{3}{|l|}{$23(19.33 \%)$} \\
\hline$\leq 20 \%$ & \multicolumn{3}{|l|}{$96(80.67 \%)$} \\
\hline \multicolumn{4}{|l|}{$>20 \%$} \\
\hline & & PCR \% & $\mathrm{p}$ \\
\hline T1 & $8(6.72 \%)$ & $5(62.50 \%)$ & 0.3584 \\
\hline T2 & $73(61.34 \%)$ & $25(34.25 \%)$ & \\
\hline T3 & $25(21.01 \%)$ & $7(28.00 \%)$ & \\
\hline T4 & $11(9.24 \%)$ & $4(36.25 \%)$ & \\
\hline Tx & $2(1.68 \%)$ & $0(0 \%)$ & \\
\hline NO & $52(43.70 \%)$ & $21(40.38 \%)$ & 0.2435 \\
\hline N1 & $44(36.97 \%)$ & $15(34.09 \%)$ & \\
\hline N2 & $19(15.97 \%)$ & $3(15.78 \%)$ & \\
\hline N3 & $4(3.36 \%)$ & $2(50.00 \%)$ & \\
\hline MO & $111(93.28 \%)$ & $40(34.48 \%)$ & 0.1670 \\
\hline M1 & $8(6.62 \%)$ & $1(12.50 \%)$ & \\
\hline $\mathrm{G} 1$ & $8(6.72 \%)$ & $1(12,50 \%)$ & 0.0078 \\
\hline G2 & $61(51.26 \%)$ & $15(24,59 \%)$ & \\
\hline G3 & 50 (42.02\%) & $25(50,00 \%)$ & \\
\hline
\end{tabular}




\begin{tabular}{|c|c|c|c|}
\hline \multicolumn{4}{|l|}{$n=119$} \\
\hline LA & 13 (10.92\%) & $0(0 \%)$ & 0.0003 \\
\hline LB & 37 (31.09\%) & $6(16.66 \%)$ & \\
\hline HER2-LB & 26 (21.85\%) & 10 (38.46\%) & \\
\hline HER2-NL & 19 (15.97\%) & 10 (52.63\%) & \\
\hline TNBC & 24 (20.17\%) & 15 (62.50\%) & \\
\hline $\mathrm{TCH} / \mathrm{TCH}+\mathrm{P}$ & 44 (36.97\%) & & \\
\hline $4 \times A C+12 \times P X L$ & 61 (51.26\%) & & \\
\hline Hormonal & $14(11.76 \%)$ & & \\
\hline Radiotherapy & 90 (75.63\%) & & \\
\hline
\end{tabular}

Table 1. Patient characteristics and PCR outcomes. $(p<0,05), E R, P G R, H E R 2(+)-$ estrogen, progesterone HER2 receptor positive, TNM 8th edition clinical classification, G1; G2; G3 - histological malignancy grade in NGS score, LA - luminal A, LB- luminal B, HER2-LB - luminal B HER2 enriched, HER2-NL - nonluminal HER2 positive, TNBC - triple negative breast cancer, TCH/ TCH+P (docetaxel, carboplatin, trastuzumab +/- pertuzumab), 4xAC + 12xPXL - 4x (doxorubicin + cyclophosphamide) $+12 x$ paclitaxel

The concentrations of the investigated markers were determined in the blood samples of the patients collected before the initiation of NAT and control group (Figure 2A-C). The tests were performed at the Laboratory of Tumor Markers NIO-PIB. ROC curves were designated to estimate the diagnostic value of HER3, AURKA and TK1. The areas under the ROC curves were respectively: for HER3 -0.634 (95\% Cl: 0.524-0.745), for AURKA - 0.453 (95\% Cl: $0.351-0.555)$ and for TK1 - 0.847 (95\% Cl: $0.771-0.923)$. The fields for HER3 and TK1 differed statistically significantly from 0.5 ; $p$ values for HER3 $-p=0.02$; for TK1 $p<0.001$. The results are presented in Figure 2.

The univariate analysis using $\chi 2$ independence test was performed to correlate PCR with marker serum levels. The concentration cut-offs were chosen to divide patients into three equal groups, which provides the best chance of detecting a relationship between PCR and the test variables. A statistically significant relationship was found between PCR and AURKA concentration $(p=0.039)$. No similar relationship was found for HER3 ( $p=0.712)$ and TK1 $(p=0.466)$. PCR rates for AURKA levels $(<4.75 \mathrm{ng} / \mathrm{mL} ; 4.75-6.66 \mathrm{ng}$ $/ \mathrm{mL} ; \geq 6.55 \mathrm{ng} / \mathrm{mL}$ ) were respectively: $21.1 \%, 48.7 \%, 35.0 \%$. The results of the univariate analysis are presented in Figure 3.

In the next step, a multivariate analysis was performed using a logit regression model with PCR as the dependent variable. The model was built based on clinical parameters that may affect the response to treatment - TNM advancement level, histological grade $G$ and the status of receptors defining the biological subtype of the tumor - ER, PGR, HER2 and Ki67. 
In the multivariate analysis, the effect of AURKA concentration $\geq 4.75 \mathrm{ng} / \mathrm{mL}$ on the chance of achieving PCR was found $(p=0.023)$, OR: 3.5 (95\% Cl: 1.2-10.1). PCR rates for values less than and greater or equal to $4.75 \mathrm{ng} / \mathrm{mL}$ are presented in Figure 4

A statistically significant effect on PCR was also found for the NO lymph node status ( $p=0.039)$, no PGR expression $(p<0.001)$ and Ki67 expression $>20 \%(p<0.025)$. The respective odds ratios (with $95 \%$ confidence interval) were: for N0 - 0.503 (95\% Cl: 0.263-0.965), for PGR (-) - 0.104 (95\% Cl: 0.038-0.284) and for Ki67> 20\% - 5.44 (95\% Cl: 1.24-23.9). Table 2 presents the parameters of the adopted logit model.

Table 2

Parameters of the adopted logit model.

\begin{tabular}{|c|c|c|c|c|c|c|}
\hline & \multirow[t]{2}{*}{$\begin{array}{l}\boldsymbol{\beta} \\
\text { coefficient }\end{array}$} & \multirow[t]{2}{*}{$\begin{array}{l}\text { Standard } \\
\text { error }\end{array}$} & \multirow[t]{2}{*}{$\begin{array}{l}p \\
\text { value }\end{array}$} & \multirow[t]{2}{*}{$\begin{array}{l}\text { Odds } \\
\text { ratio }\end{array}$} & \multicolumn{2}{|c|}{$\begin{array}{l}95 \% \text { - confidence } \\
\text { interval }\end{array}$} \\
\hline & & & & & lower & upper \\
\hline NO & -0.687 & 0.332 & 0.039 & 0.503 & 0.263 & 0.965 \\
\hline PGR (-) & -2.259 & 0.511 & $<0.001$ & 0.104 & 0.038 & 0.284 \\
\hline Ki67>20\% & 1.694 & 0.755 & 0.025 & 5.441 & 1.239 & 23.893 \\
\hline $\begin{array}{l}\text { AURKA } \\
\geq 4,75 \mathrm{ng} / \mathrm{mL}\end{array}$ & 1.244 & 0.545 & 0.023 & 3.470 & 1.192 & 10.105 \\
\hline Constant & -3.178 & 1.546 & 0.040 & 0.042 & & \\
\hline
\end{tabular}

Table 2. Parameters of the adopted logit model. Parameters of the adopted logit model - NO - no node metastasis, PGR (-) no PGR expression, significance $(p<0,05)$

To estimate the PCR - predictive value of AURKA, the ROC curve was determined - Figure 5

The estimated area under the ROC curve for AURKA with 95\% confidence interval was $0.555(95 \% \mathrm{Cl}$ : $0.452-0.658)$, the difference from the value of 0.5 was statistically insignificant $(p=0.330)$. The optimal cut-off value was $4.395 \mathrm{ng} / \mathrm{mL}$. The possibility of using the measurement of serum AURKA concentrations at the optimal cut-off value ( $\geq 4.395 \mathrm{ng} / \mathrm{mL}$ ) as a marker for PCR after NAT was assessed. The parameters for this diagnostic test were as follows: sensitivity - $92.7 \%$; specificity - $35.5 \%$; positive predictive value - $43.7 \%$; negative predictive value of $90 \%$.

\section{EXPLORATORY ANALYSIS}

The non-parametric correlation showed a statistically significant positive relationship between the concentration of AURKA and TK1 p $<0.001$; Spearman's correlation coefficient was 0.318 indicating a weak correlation. With the adopted level of statistical significance, no other correlations were found.

There was no significant correlation between biomarker concentrations and clinical features: tumor size, lymph node metastases, presence of distant metastases, expression of tumor tissue markers - ER, PGR, 
HER2 and Ki67, biological subtype, grade of histological malignancy. The obtained results along with the probability $p$ values are presented in supplement.

\section{Discussion}

This is the first study to evaluate the predictive value of serum Aurora A, thymidine kinase 1 and HER3/ErbB3 concentrations in BC patients treated with neoadjuvant chemotherapy. Currently, there are several ELISA subtypes that are widely used in laboratory diagnostics [49, 50]. Specific to HER3, AURKA and TK1 ELISA antibodies have been developed in recent years. There are ready-made commercial ELISA kits, developed by biotechnology companies, but due to poorly understood characteristics, they are intended for experimental use. The importance of Aurora A kinase tissue overexpression in the pathophysiology of cancer is the subject of many studies and AURKA is a promising target for anticancer therapies [30]. AURKA tissue expression has been demonstrated as a predictive and prognostic factor in many solid tumors. AURKA overexpression in BC cells is associated with resistance to hormone therapy, taxanes, kinase inhibitors, and deterioration of prognosis and overall survival [34,51,52]. Other studies have found that AURKA expression in TNBC and obese patients is associated with a worse prognosis and a higher relapse rate [37]. In ovarian tumors, AURKA overexpression has been associated with platinum treatment resistance and worsening of OS [53,54]. Standards for assessing tissue AURKA overexpression have not yet been developed, and one of the key limitations of the research is the different methodology, which makes it impossible to objectively compare the results. To our knowledge, this is the first study of the predictive value of serum AURKA. The results of our study indicate a positive effect of a high and negative effect of low concentration of AURKA in the serum on the effect of NAT in patients with BC. Considering the results of AURKA tissue expression studies, the observed relationships should be verified in another study on a larger group of patients. In the future, it is planned to re-evaluate OS and PFS in patients participating in this study, 5 and 10 years after treatment, to determine the prognostic value of serum AURKA. Due to alternative splicing, HER3 occurs in the human body in the form of 3 isoforms - p180, p85 and p45 [36], which can be detected in peripheral blood by ELISA [44, 55]. The commercially available ELISA kits differ from each other in the type of HER3-specific antibodies, which may affect the obtained results [44]. There are studies showing the different role of individual HER3 isoforms in the pathology of neoplasms. F. Vakar-Lopez et al. demonstrated different expression of p180 and p45 HER3 isoforms in epithelial and stromal cells of the prostate, and in addition, overexpression of p45 HER3 was shown in metastatic prostate cancer cells in lymph nodes and bones [56]. C. Li et al. demonstrated a key role of the intracellular domain of HER3 in the pathways promoting the colonization and proliferation of TNBC metastases within the bone [57].However, the importance of individual HER3 isoforms in the biology of breast cancer has not been studied so far. The manufacturer of the ELISA kit used in this study did not define the specificity of the antibodies used in relation to HER3 isoforms. There are studies that have shown the diagnostic and prognostic value of HER3 in patients with liver disease $[58,59]$. In our study serum HER3 did not correlate with the achievement of PCR after NAT $(p=0.712)$. Despite the statistically significant difference in HER3 concentrations in the control and BC groups $(p=$ 0.02), it should be assumed that factors independent of BC influence the increase in serum sHER3 levels 
and it is not applicable as a diagnostic marker in breast cancer. Although HER3 has extremely important role in the cancer pathophysiology and resistance mechanisms to the current anti-HER2 therapy $[36,60]$, due to the lack of standardization of the assay methods, the presence of isoforms with different biological significance and low tissue specificity, use of serum HER3 is currently limited. TK1 thymidine kinase is an essential enzyme in the process of DNA synthesis and repair. TK1 is released from cells that break down when they divide, a phenomenon that is typical of cancer. After being released into the extracellular space, TK1 polymerizes to form complex protein complexes of different mass and activity, depending on the tissue it comes from [61]. Two types of methods for measuring TK1 in serum have been developed - the enzymatic activity of TK1 is measured or the concentration of TK1 mass in a given volume is determined using IHC techniques [46]. Measurement of the TK1 enzymatic activity is based on the detection of specially labeled TK1 substrates by various phosphorylation methods [62-64]. Studies proved clinical use of TK1 activity for prognosing and monitoring the treatment of patients with leukemia and lymphoma [65-68]. The given methods, however, show different sensitivity depending on the masses of the tested TK1 complexes, which influences the obtained results. It has also been proven that in the case of solid tumors - breast and prostate cancer, a large percentage of TK1 is released into the serum in an inactive form [61]. An additional problem in assessing the activity of TK1 is the presence of TK1 inhibitors in the serum [69]. Due to the mentioned limitations of techniques for measuring TK1 activity, attempts were made to develop methods based on the detection of TK1 with specific antibodies [70]. Studies have shown an adverse effect of high concentrations of TK1 on OS and DFS [48, 71-73]. Our study showed no correlation between PCR after NAT and serum TK1 concentration. We found significantly higher TK1 in control group than in BC group, but given that many conditions have been reported (including viral infections), which may cause an increase in serum TK1 [70, 74], it should be considered that TK1 is not a diagnostic marker in breast cancer. The limitations of this study were clinically disproportionate BC group, and the small and probably heterogeneous control group. The likely influence of other, non-cancerous factors on tested markers should also be emphasized.

\section{Conclusions}

Serum AURKA may be a predictive marker in BC patients treated with NAT. Serum HER3, AURKA and TK1 cannot differentiate women with breast cancer from healthy women. HER3 and TK1 concentrations in serum of BC patients treated with NAT are not PCR predictive markers. The concentrations of HER3, AURKA and TK1 in the blood serum in patients with breast cancer before NAT are not related known predictors.

\section{Declarations}

\section{Funding}

This study was financed by generous support from the Count Jakub Potocki Foundation, Grant ID 36/19.

\section{AUTHOR INFORMATION}

Page $11 / 22$ 


\section{Affiliations}

Department of Breast Cancer and Reconstructive Surgery, Maria Sklodowska-Curie National Research Institute of Oncology, Warsaw, Poland

Pawel Winter; Agnieszka Jagiello-Gruszfeld; Zbigniew Nowecki

Department of Pathology and Laboratory Diagnostics, Laboratory of Tumor Markers, Maria SklodowskaCurie National Research Institute of Oncology Warsaw, Poland

Beata Kotowicz; Malgorzata Fuksiewicz; Maria Kowalska

\section{Contributions}

P. W. \& B. K. Equal contribution to research work or shared first co-authors, study design, data collection, statistical analysis, prepared tables, figures, wrote manuscript; M. F. \& M. K. performed experiments and collected data; A. J-G. clinical data analysis, contributed to the discussion of the results; Z. N. review of the manuscript and overall supervision; All authors read the manuscript and approved

\section{Competing interests}

The authors declare no competing interests.

\section{References}

1. Sung H, Ferlay J, Siegel RL, Laversanne M, Soerjomataram I, Jemal A, i in. Global cancer statistics 2020: GLOBOCAN estimates of incidence and mortality worldwide for 36 cancers in 185 countries. CA Cancer J Clin 2021:caac.21660. https:// doi.org/10.3322/caac.21660.

2. Koboldt DC, Fulton RS, McLellan MD, Schmidt H, Kalicki-Veizer J, McMichael JF, i in. Comprehensive molecular portraits of human breast tumours. Nature 2012;490:61-70. https://doi.org/10.1038/nature11412.

3. Shah SP, Roth A, Goya R, Oloumi A, Ha G, Zhao Y, i in. The clonal and mutational evolution spectrum of primary triple-negative breast cancers. Nature 2012;486:395-9. https://doi.org/10.1038/nature10933.

4. Asselain B, Barlow W, Bartlett J, Bergh J, Bergsten-Nordström E, Bliss J, i in. Long-term outcomes for neoadjuvant versus adjuvant chemotherapy in early breast cancer: meta-analysis of individual patient data from ten randomised trials. Lancet Oncol 2018;19:27-39. https://doi.org/10.1016/S1470-2045(17)30777-5.

5. Provenzano E, Bossuyt V, Viale G, Cameron D, Badve S, Denkert C, i in. Standardization of pathologic evaluation and reporting of postneoadjuvant specimens in clinical trials of breast cancer: Recommendations from an international working group. Mod Pathol 2015;28:1185-201. https://doi.org/10.1038/modpathol.2015.74. 
6. Müller HD, Posch F, Suppan C, Bargfrieder U, Gumpoldsberger M, Hammer R, i in. Validation of Residual Cancer Burden as Prognostic Factor for Breast Cancer Patients After Neoadjuvant Therapy. Ann Surg Oncol 2019;26:4274-83. https://doi.org/10.1245/s10434-019-07741-w.

7. Symmans WF, Wei C, Gould R, Yu X, Zhang Y, Liu M, i in. Long-Term Prognostic Risk After Neoadjuvant Chemotherapy Associated With Residual Cancer Burden and Breast Cancer Subtype. J Clin Oncol 2017;35:1049-60. https://doi.org/10.1200/JC0.2015.63.1010.

8. Campbell JI, Yau C, Krass P, Moore D, Carey LA, Au A, i in. Comparison of residual cancer burden, American Joint Committee on Cancer staging and pathologic complete response in breast cancer after neoadjuvant chemotherapy: results from the I-SPY 1 TRIAL (CALGB 150007/150012; ACRIN 6657). Breast Cancer Res Treat 2017;165:181-91. https://doi.org/10.1007/s10549-017-4303-8.

9. Livingston-Rosanoff D, Schumacher J, Vande Walle K, Stankowski-Drengler T, Greenberg CC, Neuman $\mathrm{H}$, i in. Does Tumor Size Predict Response to Neoadjuvant Chemotherapy in the Modern Era of Biologically Driven Treatment? A Nationwide Study of US Breast Cancer Patients. Clin Breast Cancer 2019;19:e741-7. https://doi.org/10.1016/j.clbc.2019.05.014.

10. Jameson JL, Longo DL. Precision Medicine - Personalized, Problematic, and Promising. N Engl J Med 2015;372:2229-34. https://doi.org/10.1056/NEJMsb1503104.

11. Naito Y, Urasaki T. Precision medicine in breast cancer. Chinese Clin Oncol 2018;7:29-29. https://doi.org/10.21037/cco.2018.06.04.

12. Jagiello-Gruszfeld Al, Pogoda K, Niwinska A, Lemanska I, Szombara E, Gorniak A, i in. Are anthracyclines needed for the neoadjuvant treatment of patients with HER2-positive early breast cancer? J Clin Oncol 2018;36:e12599-e12599.

https://doi.org/10.1200/JC0.2018.36.15_suppl.e12599.

13. Jagiello-Gruszfeld Al, Lemanska I, Sienkiewicz R, Szombara E, Dubianski R, Brewczynska E, i in. Pathological outcomes of HER2-positive early breast cancer patients treated with neoadjuvant trastuzumab or dual anti-HER2 therapy and carboplatin with docetaxel: A Maria Sklodowska-Curie National Research Institute of Oncology experience. J Clin Oncol 2020;38:e12655-e12655. https://doi.org/10.1200/JC0.2020.38.15_suppl.e12655.

14. Duffy MJ, O'Donovan N, McDermott E, Crown J. Validated biomarkers: The key to precision treatment in patients with breast cancer. Breast 2016;29:192-201. https://doi.org/10.1016/j.breast.2016.07.009.

15. Loke SY, Lee ASG. The future of blood-based biomarkers for the early detection of breast cancer. Eur J Cancer 2018;92:54-68. https://doi.org/10.1016/j.ejca.2017.12.025.

16. Macdonald S, Oncology R, General M. Breast Cancer Breast Cancer. J R Soc Med 2016;70:515-7.

17. Jassem J, Krzakowski M. Breast cancer. Oncol Clin Pract 2018;14:171-215. https://doi.org/10.5603/OCP.2018.0027.

18. Lin DC, Genzen JR. Concordance analysis of paired cancer antigen (CA) 15-3 and 27.29 testing. Breast Cancer Res Treat 2018;167:269-76. https://doi.org/10.1007/s10549-017-4513-0. 
19. Van Poznak C, Somerfield MR, Bast RC, Cristofanilli M, Goetz MP, Gonzalez-Angulo AM, i in. Use of Biomarkers to Guide Decisions on Systemic Therapy for Women With Metastatic Breast Cancer: American Society of Clinical Oncology Clinical Practice Guideline. J Clin Oncol 2015;33:2695-704. https://doi.org/10.1200/JC0.2015.61.1459.

20. Magnaghi-Jaulin L, Eot-Houllier G, Gallaud E, Giet R. Aurora a protein kinase: To the centrosome and beyond. Biomolecules 2019;9. https://doi.org/10.3390/biom9010028.

21. Guarino Almeida E, Renaudin X, Venkitaraman AR. A kinase-independent function for AURORA-A in replisome assembly during DNA replication initiation. Nucleic Acids Res 2020;48:7844-55. https://doi.org/10.1093/nar/gkaa570.

22. Marumoto T, Hirota T, Morisaki T, Kunitoku N, Zhang D, Ichikawa $Y$, i in. Roles of aurora-A kinase in mitotic entry and G2 checkpoint in mammalian cells. Genes to Cells 2002;7:1173-82. https://doi.org/10.1046/j.1365-2443.2002.00592.x.

23. Korobeynikov V, Deneka AY, Golemis EA. Mechanisms for nonmitotic activation of Aurora-A at cilia. Biochem Soc Trans 2017;45:37-49. https://doi.org/10.1042/BST20160142.

24. Sardon T, Pache RA, Stein A, Molina H, Vernos I, Aloy P. Uncovering new substrates for aurora a kinase. EMBO Rep 2010;11:977-84. https://doi.org/10.1038/embor.2010.171.

25. Carvalhal S, Ribeiro SA, Arocena M, Kasciukovic T, Temme A, Koehler K, i in. The nucleoporin ALADIN regulates Aurora A localization to ensure robust mitotic spindle formation. Mol Biol Cell 2015;26:3424-38. https://doi.org/10.1091/mbc.E15-02-0113.

26. Kulbe, Otto, Darb-Esfahani, Lammert, Abobaker, Welsch, i in. Discovery and Validation of Novel Biomarkers for Detection of Epithelial Ovarian Cancer. Cells 2019;8:713. https://doi.org/10.3390/cells8070713.

27. Yan $M$, Wang $C$, He B, Yang M, Tong M, Long Z, i in. Aurora-A Kinase: A Potent Oncogene and Target for Cancer Therapy. Med Res Rev 2016;36:1036-79. https://doi.org/10.1002/med.21399.

28. Nikonova AS, Astsaturov I, Serebriiskii IG, Dunbrack RL, Golemis EA. Aurora A kinase (AURKA) in normal and pathological cell division. Cell Mol Life Sci 2013;70:661-87. https://doi.org/10.1007/s00018-012-1073-7.

29. Asteriti IA, Di Cesare E, De Mattia F, Hilsenstein V, Neumann B, Cundari E, i in. The Aurora-A inhibitor MLN8237 affects multiple mitotic processes and induces dose-dependent mitotic abnormalities and aneuploidy. Oncotarget 2014;5:6229-42. https://doi.org/10.18632/oncotarget.2190.

30. Du R, Huang C, Liu K, Li X, Dong Z. Targeting AURKA in Cancer: molecular mechanisms and opportunities for Cancer therapy. Mol Cancer 2021;20:15. https://doi.org/10.1186/s12943-02001305-3.

31. Kimura M, Takagi S, Nakashima S. Aurora A regulates the architecture of the Golgi apparatus. Exp Cell Res 2018;367:73-80. https://doi.org/10.1016/j.yexcr.2018.03.024.

32. Bertolin G, Bulteau AL, Alves-Guerra MC, Burel A, Lavault MT, Gavard O, i in. Aurora kinase a localises to mitochondria to control organelle dynamics and energy production. Elife 2018;7:1-28. https://doi.org/10.7554/eLife.38111. 
33. Zheng F, Yue C, Li G, He B, Cheng W, Wang X, i in. Nuclear AURKA acquires kinase-independent transactivating function to enhance breast cancer stem cell phenotype. Nat Commun 2016;7:10180. https://doi.org/10.1038/ncomms10180.

34. Lykkesfeldt AE, Iversen BR, Jensen MB, Ejlertsen B, Giobbie-Hurder A, Reiter BE, i in. Aurora kinase A as a possible marker for endocrine resistance in early estrogen receptor positive breast cancer. Acta Oncol (Madr) 2018;57:67-73. https://doi.org/10.1080/0284186X.2017.1404126.

35. Yarden Y, Sliwkowski MX. Untangling the ErbB signalling network. Nat Rev Mol Cell Biol 2001;2:12737. https://doi.org/10.1038/35052073.

36. Mishra R, Alanazi S, Yuan L, Solomon T, Thaker TM, Jura N, i in. Activating HER3 mutations in breast cancer. Oncotarget 2018;9:27773-88. https://doi.org/10.18632/oncotarget.25576.

37. Lin S-H, Lee Y-C, Choueiri MB, Wen S, Mathew P, Ye X, i in. Soluble ErbB3 Levels in Bone Marrow and Plasma of Men with Prostate Cancer. Clin Cancer Res 2008;14:3729-36. https://doi.org/10.1158/1078-0432.CCR-08-0472.

38. Campbell MR, Amin D, Moasser MM. HER3 comes of age: New insights into its functions and role in signaling, tumor biology, and cancer therapy. Clin Cancer Res 2010;16:1373-83. https://doi.org/10.1158/1078-0432.CCR-09-1218.

39. Miricescu D, Totan A, Stanescu-Spinu I-I, Badoiu SC, Stefani C, Greabu M. PI3K/AKT/mTOR Signaling Pathway in Breast Cancer: From Molecular Landscape to Clinical Aspects. Int J Mol Sci 2020;22:173. https://doi.org/10.3390/ijms22010173.

40. Black LE, Longo JF, Carroll SL. Mechanisms of Receptor Tyrosine-Protein Kinase ErbB-3 (ERBB3) Action in Human Neoplasia. Am J Pathol 2019;189:1898-912. https://doi.org/10.1016/j.ajpath.2019.06.008.

41. Menendez JA, Mehmi I, Papadimitropoulou A, Vander Steen T, Cuyàs E, Verdura S, i in. Fatty Acid Synthase Is a Key Enabler for Endocrine Resistance in Heregulin-Overexpressing Luminal B-Like Breast Cancer. Int J Mol Sci 2020;21:7661. https://doi.org/10.3390/ijms21207661.

42. Mizuno T, Kojima Y, Yonemori K, Yoshida H, Sugiura Y, Ohtake Y, i in. Neoadjuvant chemotherapy promotes the expression of HER3 in patients with ovarian cancer. Oncol Lett 2020;20:336. https://doi.org/10.3892/ol.2020.12200.

43. Karachaliou N, Lazzari C, Verlicchi A, Sosa AE, Rosell R. HER3 as a Therapeutic Target in Cancer. BioDrugs 2017;31:63-73. https://doi.org/10.1007/s40259-016-0205-2.

44. D'Abronzo LS, Pan C-X, Ghosh PM. Evaluation of Protein Levels of the Receptor Tyrosine Kinase ErbB3 in Serum, 2018, s. 319-34. https://doi.org/10.1007/978-1-4939-7234-0_22.

45. Welin M, Kosinska U, Mikkelsen NE, Carnrot C, Zhu C, Wang L, i in. Structures of thymidine kinase 1 of human and mycoplasmic origin. Proc Natl Acad Sci U S A 2004;101:17970-5. https://doi.org/10.1073/pnas.0406332102.

46. Jagarlamudi KK, Shaw M. Thymidine kinase 1 as a tumor biomarker: Technical advances offer new potential to an old biomarker. Biomark Med 2018;12:1035-48. https://doi.org/10.2217/bmm-20180157. 
47. Weagel EG, Burrup W, Kovtun R, Velazquez EJ, Felsted AM, Townsend MH, i in. Membrane expression of thymidine kinase 1 and potential clinical relevance in lung, breast, and colorectal malignancies. Cancer Cell Int 2018;18:135. https://doi.org/10.1186/s12935-018-0633-9.

48. Wang Z, Zhang W, Huo B, Dong L, Zhang J. Relationship between thymidine kinase 1 before radiotherapy and prognosis in breast cancer patients with diabetes. Biosci Rep 2020;40:1-8. https://doi.org/10.1042/BSR20192813.

49. Aydin S. A short history, principles, and types of ELISA, and our laboratory experience with peptide/protein analyses using ELISA. Peptides 2015;72:4-15. https://doi.org/10.1016/j.peptides.2015.04.012.

50. Hornbeck P V. Enzyme-Linked Immunosorbent Assays. Curr Protoc Immunol 2015;110:2.1.1-2.1.23. https://doi.org/10.1002/0471142735.im0201s110.

51. Cirak Y, Furuncuoglu Y, Yapicier O, Aksu A, Cubukcu E. Aurora a overexpression in breast cancer patients induces taxane resistance and results in worse prognosis. J BUON 2015;20:1414-9.

52. Wander SA, Cohen O, Gong X, Johnson GN, Buendia-Buendia JE, Lloyd MR, i in. The Genomic Landscape of Intrinsic and Acquired Resistance to Cyclin-Dependent Kinase 4/6 Inhibitors in Patients with Hormone Receptor-Positive Metastatic Breast Cancer. Cancer Discov 2020;10:1174-93. https:// doi.org/10.1158/2159-8290.CD-19-1390.

53. Mignogna C, Staropoli N, Botta C, De Marco C, Rizzuto A, Morelli M, i in. Aurora Kinase A expression predicts platinum-resistance and adverse outcome in high-grade serous ovarian carcinoma patients. J Ovarian Res 2016;9:1-8. https://doi.org/10.1186/s13048-016-0238-7.

54. Li M, Li H, Liu F, Bi R, Tu X, Chen L, i in. Characterization of ovarian clear cell carcinoma using target drug-based molecular biomarkers: implications for personalized cancer therapy. J Ovarian Res 2017;10:9. https://doi.org/10.1186/s13048-017-0304-9.

55. Broughton MN, Westgaard A, Paus E, Øijordsbakken M, Henanger KJ, Naume B, i in. Specific antibodies and sensitive immunoassays for the human epidermal growth factor receptors (HER2, HER3, and HER4). Tumor Biol 2017;39. https://doi.org/10.1177/1010428317707436.

56. Vakar-Lopez F, Cheng C-J, Kim J, Shi GG, Troncoso P, Tu S-M, i in. Up-regulation of MDA-BF-1, a secreted isoform of ErbB3, in metastatic prostate cancer cells and activated osteoblasts in bone marrow. J Pathol 2004;203:688-95. https://doi.org/10.1002/path.1568.

57. Li C, Wang S, Xing Z, Lin A, Liang K, Song J, i in. A ROR1-HER3-IncRNA signalling axis modulates the Hippo-YAP pathway to regulate bone metastasis. Nat Cell Biol 2017;19:106-19. https://doi.org/10.1038/ncb3464.

58. Hsieh S-Y, He J-R, Yu M-C, Lee W-C, Chen T-C, Lo S-J, i in. Secreted ERBB3 Isoforms Are Serum Markers for Early Hepatoma in Patients with Chronic Hepatitis and Cirrhosis. J Proteome Res 2011;10:4715-24. https://doi.org/10.1021/pr200519q.

59. Caviglia GP, Abate ML, Rolle E, Carucci P, Armandi A, Rosso C, i in. The Clinical Role of Serum Epidermal Growth Factor Receptor 3 in Hepatitis C Virus-Infected Patients with Early Hepatocellular Carcinoma. Biology (Basel) 2021;10:215. https://doi.org/10.3390/biology10030215. 
60. Gutsch D, Jenke R, Büch T, Aigner A. Inhibition of HER Receptors Reveals Distinct Mechanisms of Compensatory Upregulation of Other HER Family Members: Basis for Acquired Resistance and for Combination Therapy. Cells 2021;10:272. https://doi.org/10.3390/cells10020272.

61. Jagarlamudi KK, Hansson LO, Eriksson S. Breast and prostate cancer patients differ significantly in their serum Thymidine kinase 1 (TK1) specific activities compared with those hematological malignancies and blood donors: Implications of using serum TK1 as a biomarker. BMC Cancer 2015;15:1-12. https://doi.org/10.1186/s12885-015-1073-8.

62. Nisman B, Allweis T, Kaduri L, Maly B, Gronowitz S, Hamburger T, i in. Serum thymidine kinase 1 activity in breast cancer. Cancer Biomarkers 2010;7:65-72. https://doi.org/10.3233/CBM-2010-0148.

63. Öhrvik A, Lindh M, Einarsson R, Grassi J, Eriksson S. Sensitive Nonradiometric Method for Determining Thymidine Kinase 1 Activity. Clin Chem 2004;50:1597-606. https://doi.org/10.1373/clinchem.2003.030379.

64. Munch-Petersen B. Differences in the kinetic properties of thymidine kinase isoenzymes in unstimulated and phytohemagglutinin-stimulated human lymphocytes. Mol Cell Biochem 1984;64:173-85. https://doi.org/10.1007/BF00224774.

65. Hallek M, Wanders L, Strohmeyer S, Emmerich B. Thymidine kinase: a tumor marker with prognostic value for non-Hodgkin's lymphoma and a broad range of potential clinical applications. Ann Hematol 1992;65:1-5. https://doi.org/10.1007/BF01715117.

66. Hallek M, Emmerich B, Strohmeyer S, Busch R, Reichle A, Senekowitsch R. Activity of serum thymidine kinase in non-Hodgkin lymphoma: Relationship to other prognostic factors. Klin Wochenschr 1988;66:718-23. https://doi.org/10.1007/BF01726414.

67. Stelmach P, Błoński JZ, Wawrzyniak E, Schweiger P, Wilandt A, Majak P, i in. Prognostic value of thymidine kinase activity in patients with chronic lymphocytic leukemia. Postepy Hig Med Dosw (Online) 2016;70:1321-30. https://doi.org/10.5604/17322693.1227556.

68. O'Neill KL, Zhang F, Li H, Fuja DG, Murray BK. Thymidine kinase 1 - A prognostic and diagnostic indicator in ALL and AML patients. Leukemia 2007;21:560-3. https://doi.org/10.1038/sj.leu.2404536.

69. He Q, Zhang P, Zou L, Li H, Wang X, Zhou S, i in. Concentration of thymidine kinase 1 in serum (STK1) is a more sensitive proliferation marker in human solid tumors than its activity. Oncol Rep 2005;14:1013-9. https://doi.org/10.3892/or.14.4.1013.

70. Bitter EE, Townsend MH, Erickson R, Allen C, O'Neill KL. Thymidine kinase 1 through the ages: a comprehensive review. Cell Biosci 2020;10:138. https://doi.org/10.1186/s13578-020-00493-1.

71. McCartney A, Biagioni C, Schiavon G, Bergqvist M, Mattsson K, Migliaccio I, i in. Prognostic role of serum thymidine kinase 1 activity in patients with hormone receptor-positive metastatic breast cancer: Analysis of the randomised phase III Evaluation of Faslodex versus Exemestane Clinical Trial (EFECT). Eur J Cancer 2019;114:55-66. https://doi.org/10.1016/j.ejca.2019.04.002.

72. Bonechi M, Galardi F, Biagioni C, De Luca F, Bergqvist M, Neumüller M, i in. Plasma thymidine kinase1 activity predicts outcome in patients with hormone receptor positive and HER2 negative metastatic 
breast cancer treated with endocrine therapy. Oncotarget 2018;9:16389-99.

https://doi.org/10.18632/oncotarget.24700.

73. Elfagieh M, Abdalla F, Gliwan A, Boder J, Nichols W, Buhmeida A. Serum tumour markers as a diagnostic and prognostic tool in Libyan breast cancer. Tumour Biol 2012;33:2371-7. https://doi.org/10.1007/s13277-012-0500-6.

74. Gronowitz JS, Källander CFR, Diderholm H, Hagberg H, Pettersson U. Application of anin vitro assay for serum thymidine kinase: Results on viral disease and malignancies in humans. Int $\mathrm{J}$ Cancer 1984;33:5-12. https://doi.org/10.1002/ijc.2910330103.

\section{Figures}

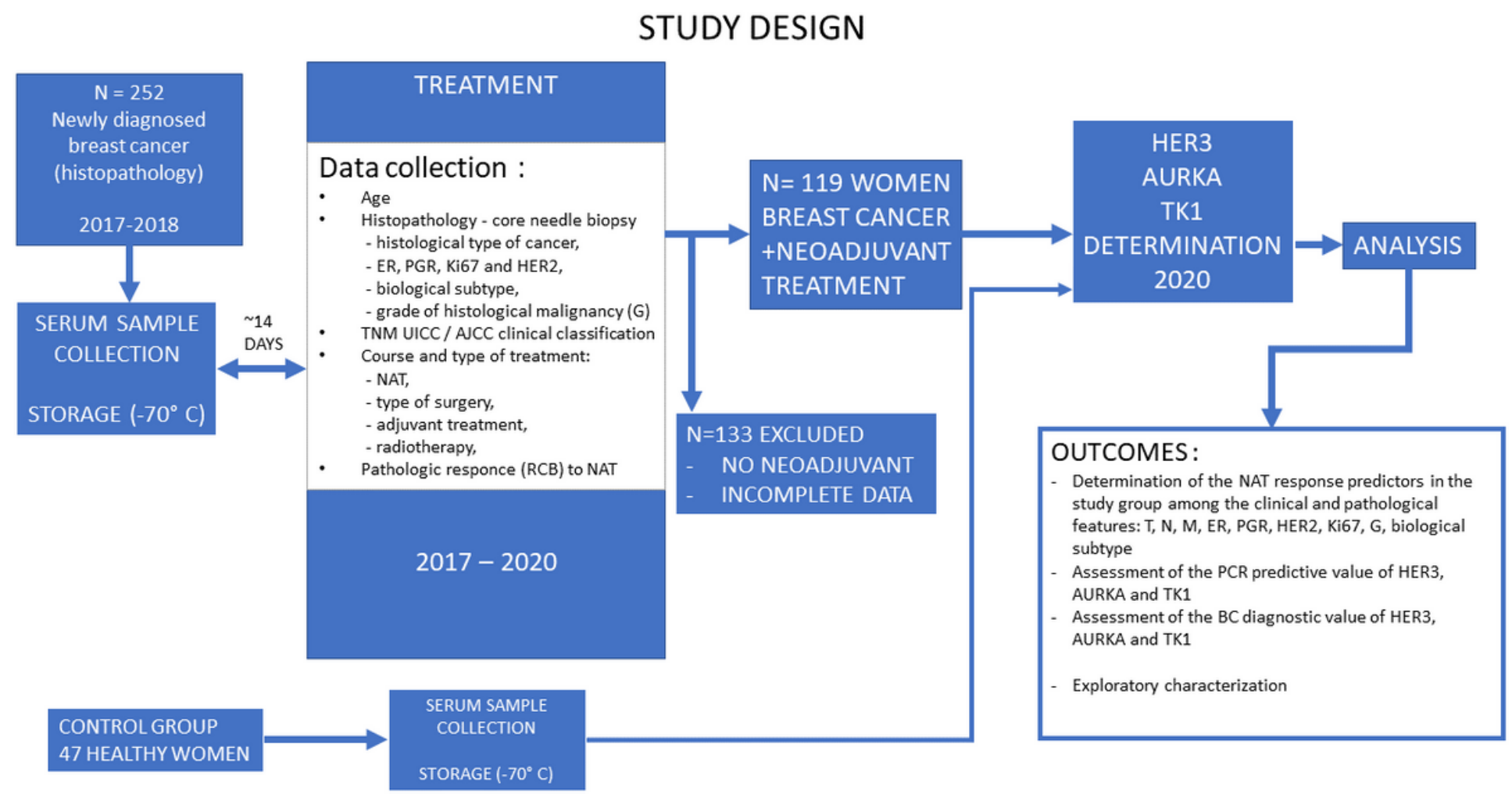

Figure 1

Study Design 

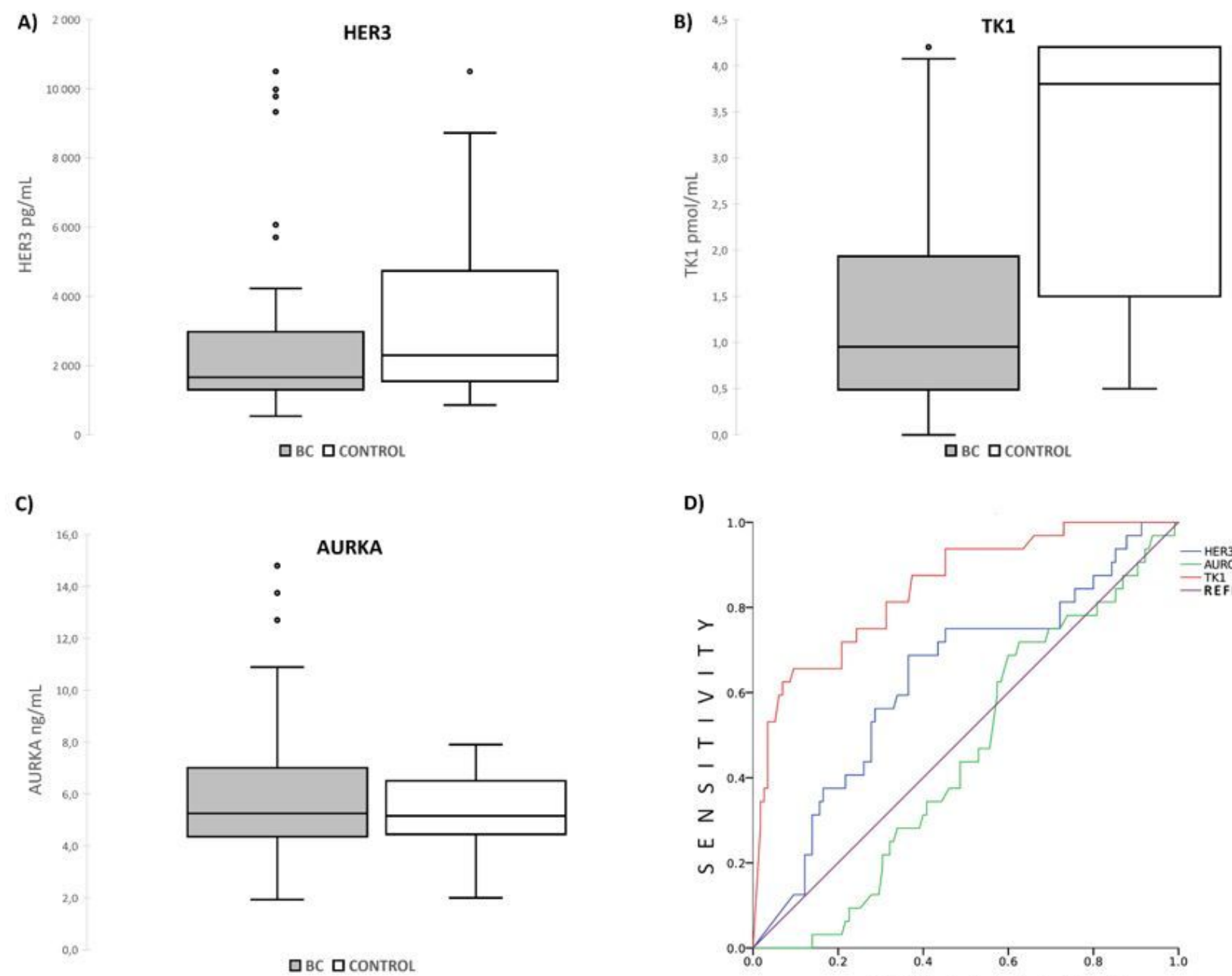

E)

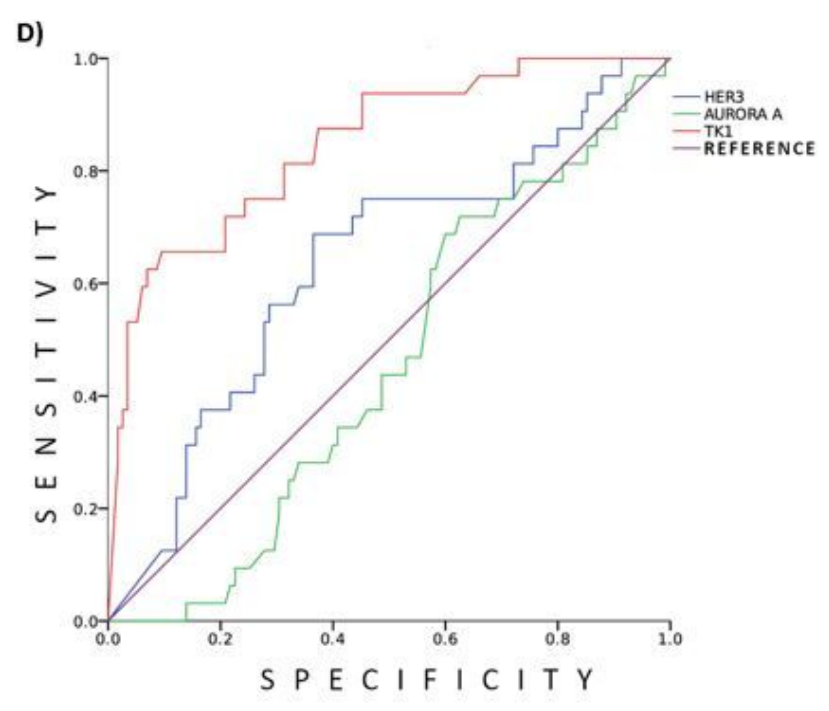

\begin{tabular}{|l|l|l|l|}
\hline \multicolumn{1}{|c|}{} & \multicolumn{1}{|c|}{ BC } & \multicolumn{1}{c|}{ Control } \\
\hline HER3 median (IQR) & $1162 \mathrm{pg} / \mathrm{mL}(1299 ; 2971)$ & $2297 \mathrm{pg} / \mathrm{mL}(1541 ; 4742)$ & \multirow{2}{*}{02} \\
min, max & $537-10500 \mathrm{pg} / \mathrm{mL}$ & $858-10500 \mathrm{pg} / \mathrm{mL}$ & \\
\hline AURORA A median (IQR) & $5.26 \mathrm{ng} / \mathrm{mL}(4.35 ; 7.00)$ & $5.15 \mathrm{ng} / \mathrm{mL}(4.44 ; 6.5)$ & \multirow{2}{*}{0,414} \\
min, max & $1.93-14.80 \mathrm{ng} / \mathrm{mL}$ & $2.0-7.9 \mathrm{ng} / \mathrm{mL}$ & \\
\hline TK1 & $0.95 \mathrm{pmol} / \mathrm{mL}(0.49 ; 1.93)$ & $3.80 \mathrm{pmol} / \mathrm{mL}(1.50 ; 4.20)$ & \\
min, max & & & $<0,001$ \\
\hline
\end{tabular}

\section{Figure 2}

HER3, AURKA and TK1 concentration range in breast cancer (BC) and control group. A) HER3 range, B) TK1 range, C) AURKA range; comparison between $B C$ and control group, D) ROC curve, E) detailed concentration values; IQR -interquartile range, non-parametric Mann-Whitney test, significance $p<0.05$ 
A)

\section{HER3}

$100,0 \%$

$80,0 \%$

$$
p=0.712
$$

$\begin{array}{ll}\text { ㄸํํ } & 60,0 \% \\ \text { ㅇํㅇ } & 40,0 \%\end{array}$

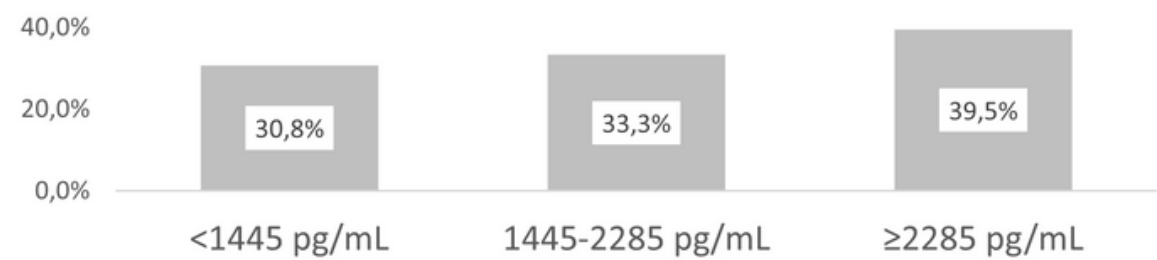

B)

\section{AURKA}

$100,0 \%$

$80,0 \%$

$$
p=0.039
$$

$\begin{array}{ll}\text { 응 } & 60,0 \% \\ \text { ㅇํㅇ } & 40,0 \%\end{array}$

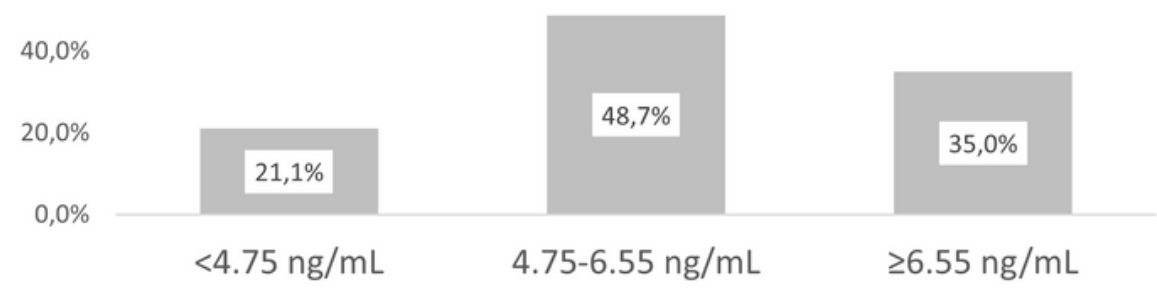

C)

\section{TK1}

$100,0 \%$

$$
p=0.466
$$

$80,0 \%$

$\begin{array}{ll}\stackrel{\Upsilon}{\cup} & 60,0 \% \\ \frac{2}{\circ} & 40,0 \%\end{array}$

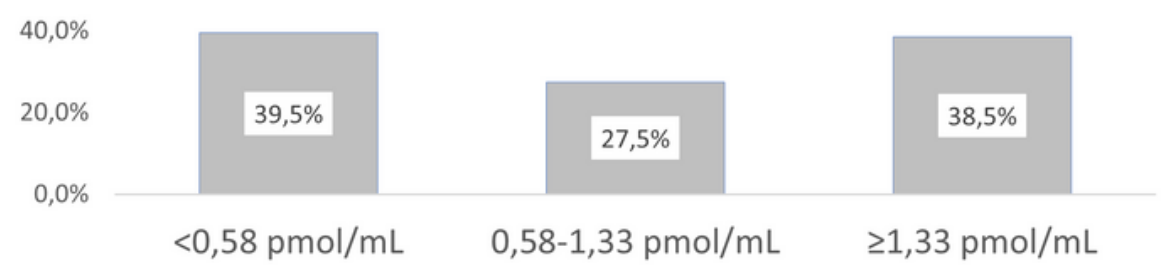

\section{Figure 3}

PCR and biomarker concentrations univariate analysis. Percentage of PCR and biomarker concentrations in selected cut-off levels, univariate analysis $(p<0,05)$ A) HER3, B) AURKA, C) TK1. 


\section{AURKA}

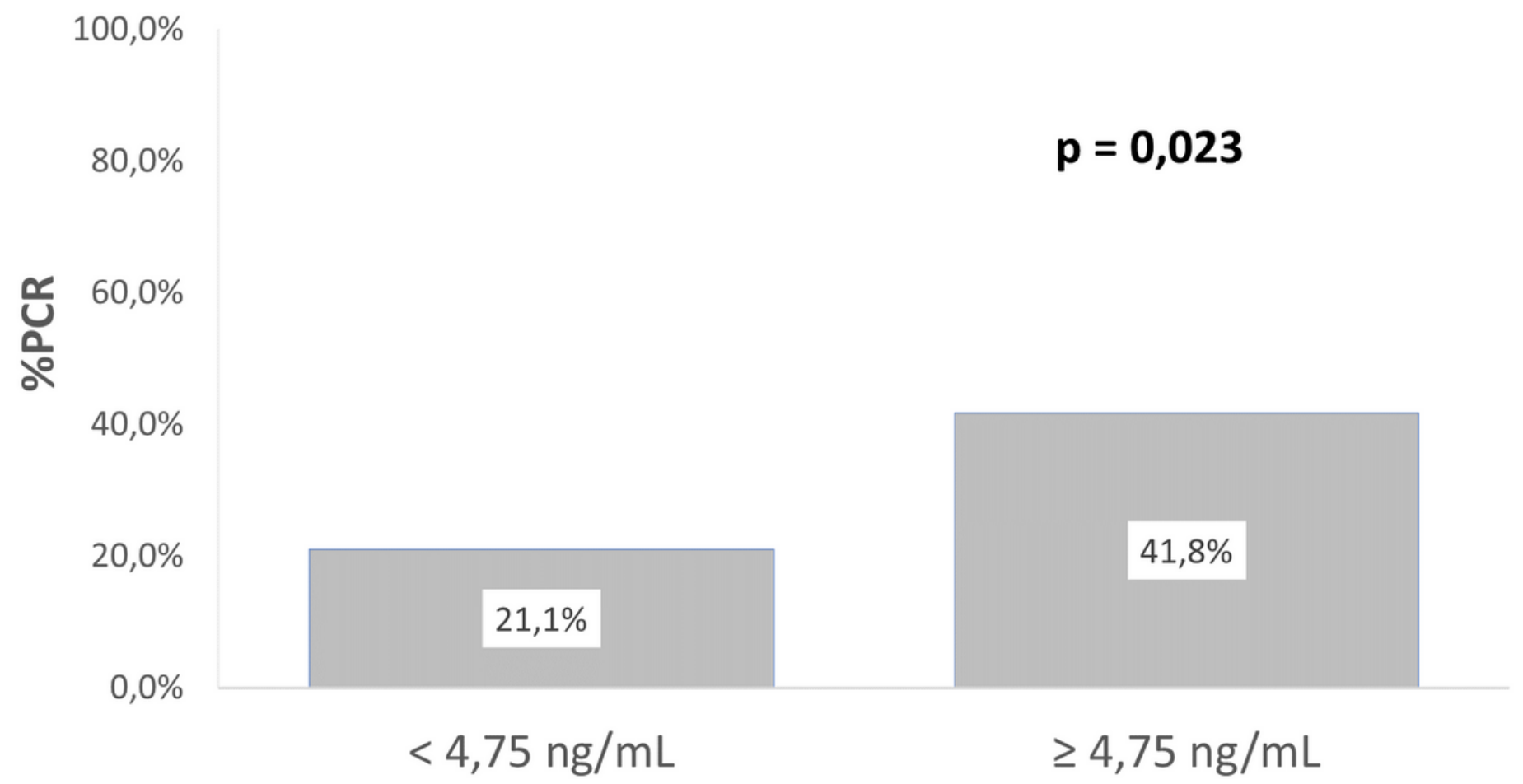

Figure 4

PCR rates depending on AURKA concentrations. Multivariate analysis. $\mathrm{p}=0.023$, OR: 3.5 (95\% Cl: 1.210.1) 


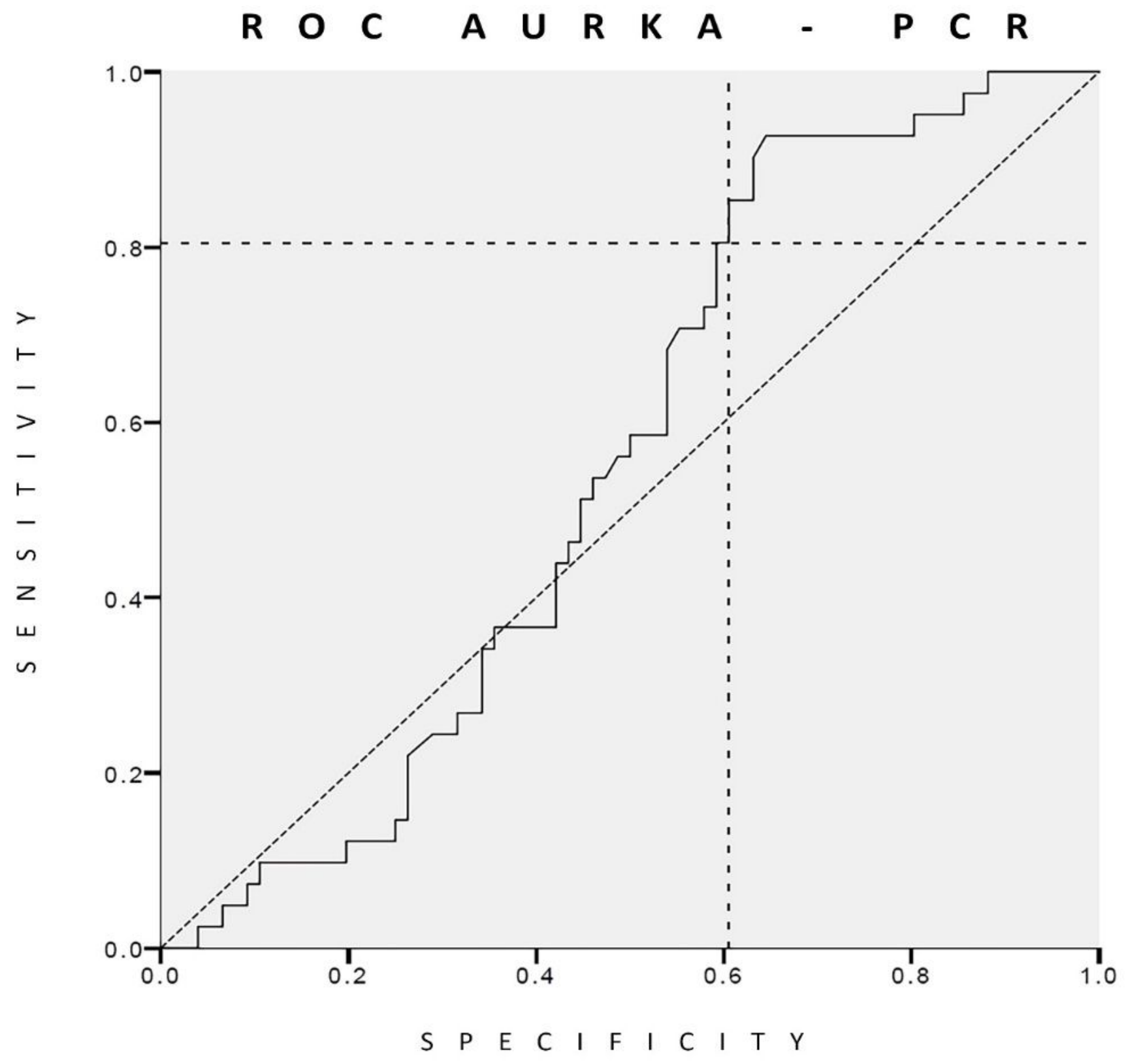

Figure 5

Receiver operating characteristic curve of AURKA - PCR.

\section{Supplementary Files}

This is a list of supplementary files associated with this preprint. Click to download.

- Supplement.pdf 